\title{
Effect of Bio-based Adhesive on Tensile Strength and Bending of Balsa Wood Adhesive Joint
}

\author{
Moch. Syamsul Ma'arif ${ }^{1 *}$, Resza Tania Putri ${ }^{1}$, Khairul Anam ${ }^{1}$ \\ ${ }^{1}$ Mechanical Engineering Department, Brawijaya University, \\ Jl. Mayjend. Haryono no. 167, Malang, 65145, INDONESIA
}

\section{*Corresponding Author}

DOI: https://doi.org/10.30880/ijie.2019.11.05.010

Received 8 January 2019; Accepted 17 April 2019; Available online 10 August 2019

\begin{abstract}
The aim of this study was to determine the effect of adhesive on tensile strength and bending strength of adhesive joints on balsa wood by varying the type of bio-based adhesive. Bio-based adhesive is very potential as a substitute for synthetic-based adhesive because of its biodegradability and non-toxic. In this research, natural adhesive was applied to specimen of balsa wood to make joint. With varied bio-based adhesives from rubber tree sap, jackfruit tree sap and breadfruit tree sap, the joined balsa wood then subjected to mechanical test. In this study, tensile testing and bending testing were conducted to determine the tensile strength and bending of balsa wood that has been joined using bio-based adhesives. The results of the research show that the variation of bio-based adhesives have effect on the strength of joined balsa wood. Since varied bio-based adhesive has different adhesive characteristics so that the tensile and bending strength of each variant which mainly caused by different binding ability between bio-based adhesive on the surfaces of balsa wood. Also, analysis of failure on join was carried out after tensile and bending tests to examine the characteristic of failure. From tensile test, the value of tensile strength from the highest one is rubber tree sap bio-based adhesive, then jackfruit sap bio-based adhesive and the lowest was breadfruit tree bio-based adhesive sap. While the results of bending testing give the highest value for adhesive rubber tree sap, then jackfruit bio-based adhesive sap and the lowest was breadfruit tree sap. This was caused primarily by the ability of each adhesive to perform good bonding on the surface of balsa wood which governed primarily by its viscosity and $\mathrm{pH}$ values.
\end{abstract}

Keywords: Bio -Based Adhesive, Adhesive Joint, Balsa Wood, Tensile Strength, Bending Strength

\section{Introduction}

In joining of materials, there are several conventional techniques that can be used to connect or joint two materials such as mechanical joining (bolts and nuts), brazing, riveting, and welding. With the growing of technology and industry, the joining technique is not only performed with the techniques above such as wood industry which has developed adhesive bonding to joint two materials. Materials joint using adhesive is a relatively easy technique compared to conventional joining technique which in special circumstances (operations) requires special techniques. In addition, the joining technique using adhesive is easily performed by all, from skilled operator/technicians to general public.

Adhesive, according to ASTM, is a substance or material that has the ability to bind two objects based on surface bonding [1]. Adhesives are one of the main ingredients that are very important in the wood processing industry. Of the total production costs of wood made in various forms, more than $32 \%$ is the cost of gluing [2] [3]. Seeing the need for high adhesives, natural materials can be used as composite materials or reinforcement instead of chemical adhesives. This natural adhesive can be used as complement to chemical adhesive because the availability of material is abundant, easily obtained and the price of raw materials is relatively lower than that of chemical adhesives. 
The use of natural materials as wood reinforcement is in line with the recommendations of FAO (Food and Agriculture Organization) to the industrial world with the issuance of "International Year of Natural Fiber 2009 (IYNF 2009) "by FAO on December 20, 2006. FAO recommends that starting in 2009 the industrial world has used raw materials that are environmentally friendly and easily degraded, especially natural materials [4].

Natural adhesive has the potential to be used as adhesives such as sap of jackfruit trees, rubber tree sap and breadfruit tree sap. These three materials have different adhesive characteristics. Rubber trees contains sap white, which is a hydrocarbon polymer formed from deciduous emulsions known as latex. Latex is developed as adhesive material from natural rubber latex which has good binding capacity [5]. Sap of jackfruit and also the trees contains polymers contained named poly-isoprene and polysaccharides. Where poly-isoprene is a natural adhesive [6]. Breadfruit stems and leaves have chemical substance including saponins, polyphenols, tannins, hydroxyic acid, acetylcholine, riboflavin, while the bark contains flavonoids. From them, tannins and flavonoids can be used as wood adhesives [7, 8, 9]. The content of each substance will govern the adsorption and its mechanical properties [10]. The application of tree sap is not only limited in joining but also in composite area, such as natural rubber [11] [12].

In this study, three variants of natural adhesive (jackfruit tree sap, rubber tree sap and breadfruit tree sap) were applied to balsa wood joint and then the tensile and bending tests were carried out the wood joint. Balsa wood is widely applied for making frames of aeromodelling and is also used for other purposes, for example, for boat buoy, boat raft, handicraft, or in the home bulilding can be used for making usuk (one of roofing component), battens, and building models. This wood was chosen because it has the characteristics of very light, easy to form, not easily decayed and has a very high level of elasticity and has a relatively low absorption of water. Balsa wood with a thickness of $12 \mathrm{~mm}$ has strength comparable to steel as thick as $3 \mathrm{~mm}$. For this purpose, balsa wood is was manufactured thru sandwich composite technique using adhesive as bonding agent [13].

Bonding balsa wood with bio-based adhesive can give good tensile strength of balsa wood sheet's joint because adhesive joints distribute the stress evenly on the joint. The type of bio-based adhesive also determines the value of tensile strength of balsa wood with adhesive joint because bio-based adhesive has different properties and characteristics depending on the sap. Therefore, the choice of bio-based adhesive determine the value of tensile and bending strength of joint.

\section{Research Methods}

The method used in this research was experimental research. Literature studies from various sources both from books, journals in the library and from the internet are also carried out to add information as needed. The first step in the research was material preparation of bio-based adhesives from rubber tree, jackfruit and breadfruit sap. Specimens were prepared by using low density balsa wood (5.2 MPa of tensile strength) and smoothened using sand paper of grid number 500, The adhesive then were applied all over $1 \mathrm{~mm}$ thick specimen surface.

Specimens shape and dimension were manufactured in compliance with specified design. Already smoothened specimen then were connected by using adhesive from natural tree sap to produce laminated balsa wood strucure. Then tensile and bending test were performed to obtain tensile and bending strength, and the region of failure were photographed.

\subsection{Tensile Test}

Before conducting this test, the specimens of balsa wood were cut first according to the design that has been determined as shown in Figure 1 below.

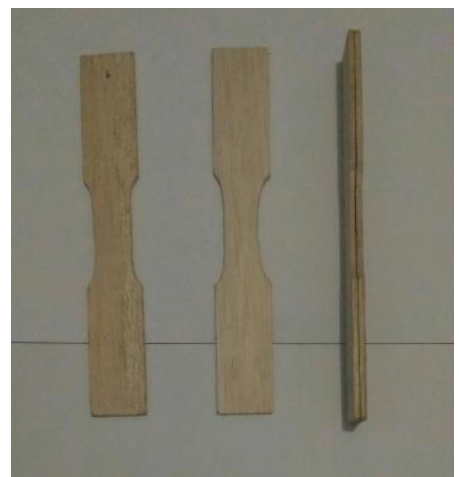

Fig. 1 Specimens of Tensile Test.

After the desired size was obtained, the specimen was tested for tensile strength to determine the maximum ability of the material to withstand tensile loads. In this test we obtained load and length of specimen during test and also got a strain stress diagram. 


\subsection{Bending Test}

Before conducting this test, the specimens of balsa wood were cut first according to the design that has been determined as shown in Figure 2 below.

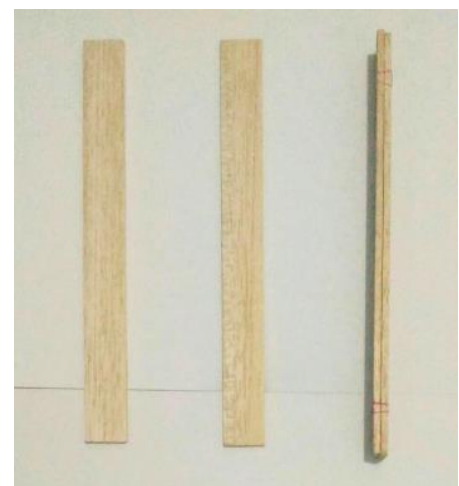

Fig. 2 - Test specimens in bending.

After desired size was obtained then the specimen was tested in bending to determine the maximum capability of the material in resisting bending loads. In this test we got load and deflection and also a strain stress diagram.

\section{Result and Discussion}

The data on tensile and bending test of specimens were given in Table 1 and Table 2.

Table 1 - Balsa Wood Test Results with Variation of Bio-based Adhesive.

\begin{tabular}{cccccc}
\hline NO & Bio-based Adhesive & $\mathbf{m m l}(\mathbf{m m})$ & F $(\mathbf{k g f})$ & $\boldsymbol{\varepsilon}(\mathbf{\%})$ & $\boldsymbol{\sigma}(\mathbf{M P a})$ \\
\hline 1. & Rubber tree sap & 11.599 & 241.105 & 7.681 & 28.129 \\
\hline 2. & Jackfruit tree sap & 13805 & 176.4 & 9.203 & 19.93 \\
\hline 3. & Sukun tree sap & 10.197 & 159.23 & 6.798 & 15.963 \\
\hline
\end{tabular}

Table 2 - Balsa Wood Test Results with Variation of Bio-based Adhesive.

\begin{tabular}{ccccc}
\hline NO & Bio-based Adhesive & $\boldsymbol{\delta}(\mathbf{m m})$ & $\mathbf{F}(\mathbf{N})$ & $\boldsymbol{\sigma}(\mathbf{M P a})$ \\
\hline 1. & Rubber tree sap & 6.353 & 113.2 & 23.58 \\
\hline 2. & Jackfruit tree sap & 6202 & 112.58 & 23.45 \\
\hline 3. & Sukun tree sap & 6.4375 & 92.08 & 19.18 \\
\hline
\end{tabular}

\subsection{Tensile Strength of Balsa Wood with Variations Bio-based Adhesive}

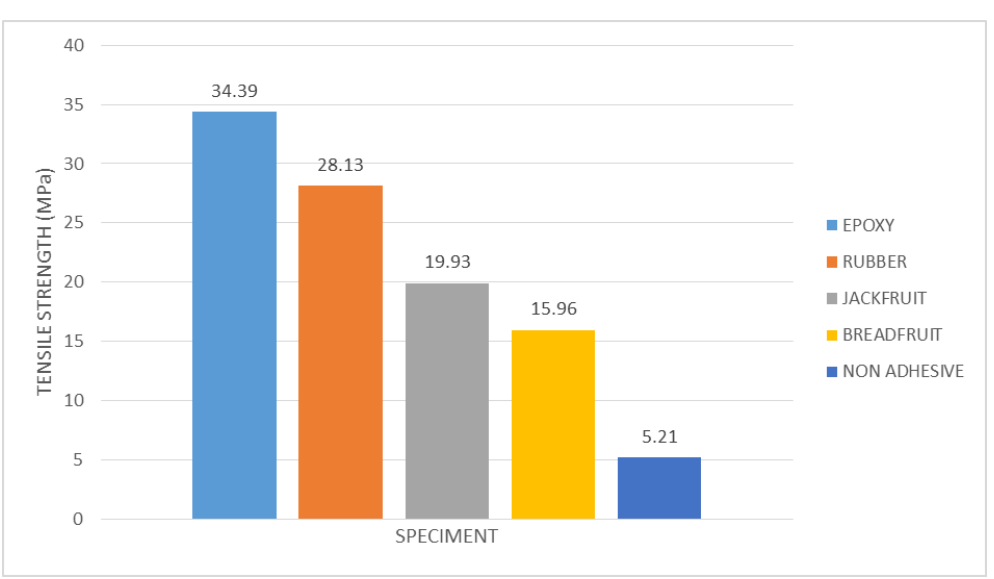

Fig. 3 - Tensile strength of balsa wood sandwich with variations of adhesives.

Figure 3 shows a comparison of the tensile strengths of adhesive joint on balsa wood by varying bio-based adhesive. It can be seen that the highest of tensile strength of specimen was for balsa wood joint using rubber tree sap adhesive, that is $28.13 \mathrm{MPa}$, then followed by jackfruit tree sap adhesive for $19.93 \mathrm{MPa}$, and the the lowest one was 
bread fruit tree sap adhesive for 15,96 MPa. The difference in strength is caused by different characteristics and properties of each natural adhesive. According to Lempang [14] rubber tree sap has a low viscosity value which makes rubber tree sap is very good in wetting the surface of the balsa wood. It make the sap able to reach void and porous site of wood surface and make the interlocking mechanism of adhesive better than others natural adhesive. It makes this tipe of adhesives has better binding strength between adhesive and adherent. Rubber tree sap also has a small $\mathrm{pH}$ value which can accelerate the drying of the sap so that the binding strength between adhesive and adherent is stronger than the sap of other trees. Those phenomena were directly proportional to the results of tearing and peeling rubber tree gum which has the highest surface binding value [15].

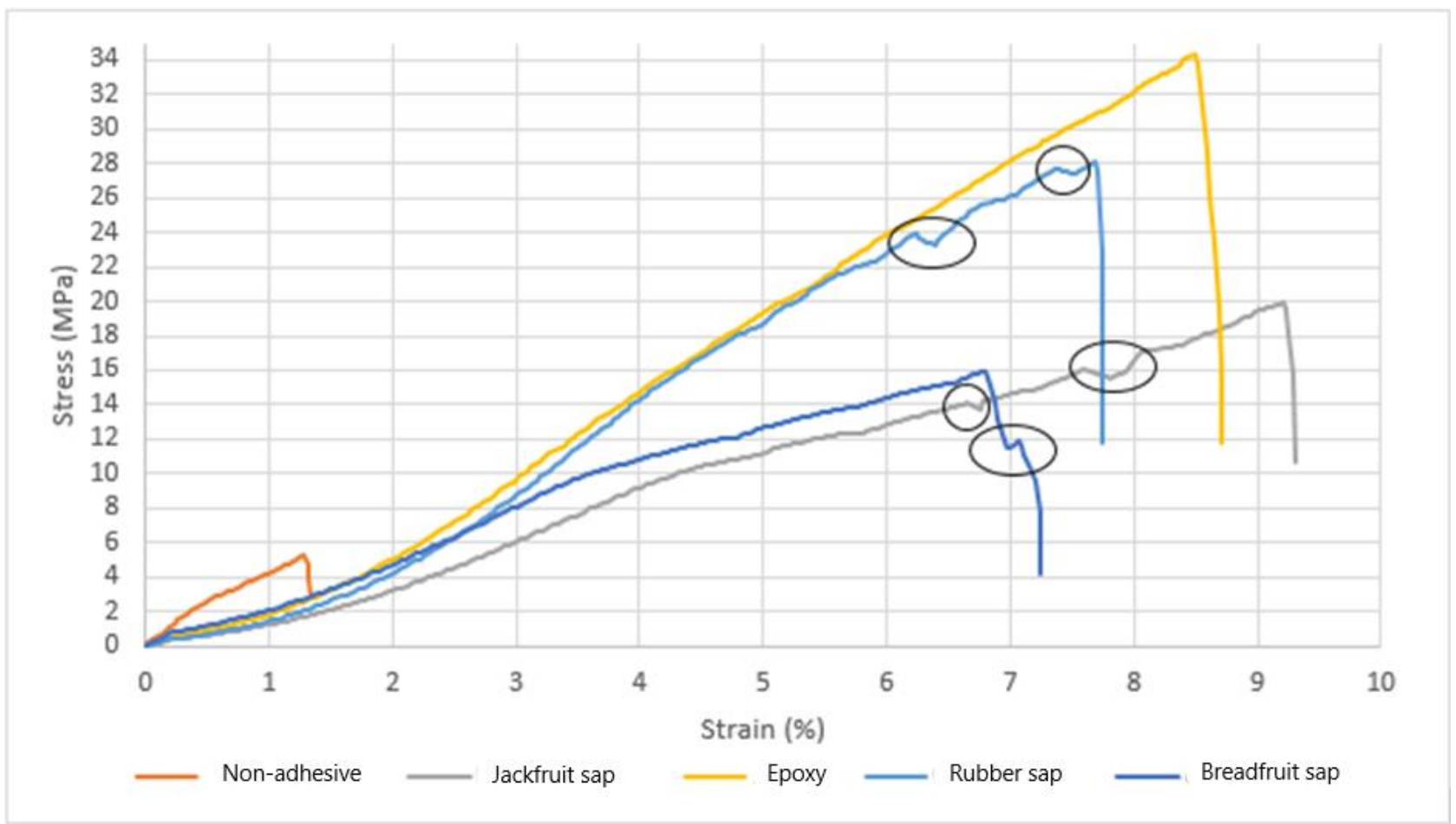

Fig. 4 - Graph stress vs strain for various adhesives on balsa wood joint.

Figure 4 shows the stress-strain relationship of balsa wood joint with variations of adhesives, i.e. epoxy, bio-based adhesive of rubber tree sap, bio-based adhesive of jackfruit tree sap and bio-based adhesive of sap of breadfruit tree. From the graph, it was obvious that all specimen experienced increasing constantly until the ultimate point then decreased.

In the strain stress graph also specifies that balsa wood sheet (without adhesive) had a lower stress and strain value compared to balsa wood with adhesive joint. The phenomenon also shows that adhesive has a function to submit and spread outthe stress to the joint and increase the stress and strain of balsa wood.

In the graph also shows that in some points there was a situation when loading does not increase smoothly but rather to decreases slightly. In this phenomenon there is a failure in the part of wood joint which called adhesive fracture. Whereas, when the load increases smoothly then another type of failure called structural fractures was occured. So that information from the stress-strain graph can illustrate how balsa wood with adhesive joint experiences failure, whether by adhesive fracture or by structural fracture.

From Figure 4 and Figure 5 (a), it can be seen that balsa wood specimens with epoxy adhesive show the type of its failure was structural failure. It shows that the bonding of adhesive from epoxy is a strong bonding and resulting in high tensile strength and also good strain distribution.

From Figure 4 and Figure 5 (b), it can be seen that balsa wood specimens with bio-based adhesive of rubber tree sap show a failure of the joining adhesive were both of mainly structural failure (structural fracture) and slight failure of adhesive (adhesive fracture). Compare to epoxy adhesive, the strength of bonding of rubber tree sap adhesive a value $70 \%$ of epoxy one. It experienced failure in adhesive when the strain value was over $7 \%$, eventough before that point it can compete with epoxy one.

According to Sucipto [16], the mechanisms of bonding between substrate are governed by three mechanisms called mechanical bonding, chemical bonding, and physical bonding. Since latex (natural adhesive) is difficult to produce new chemical substance, i.e. chemical reaction between adhesive molecule and wood molecule, then the bonding strength of the adhesive cannot exceed the epoxy one. Also, according to Blomquist [17] the system of adhesion is comprised of 9 
(nine) chains called chain 1. adhesive; chain 2 and 3. interface between adhesive; chain 4 and 5 region of interraction between adhesive and adherent; chain 6 and 7. surface of adheren; and chain 8 and 9. adherent. In relation to bonding mechanism, chain 4 and 5 , interaction region in which the chemical reaction takes place can be considered different between epoxy and latex. Since overal performance of adhesive bonding depend on interaction between all chains, then different certain chains performance will influencing the adesive bonding overall.

Eventough after 7\% strain the bonding strength of rubber tree sap cannot compete with epoxy, but it was shown that below that point the bonding strength of rubber tree sap is good. The failure of the joint occured on the balsa wood fiber and slightly fails on the adhesive. From this analysis it can be shown that the bonding of bio-based adhesive of rubber tree sap has a good bond and stress distribution.

Bio-based adhesive with rubber tree sap has potent to be used as a substitute of synthetic adhesive for low loading application. Eventough it has drawback in tensile strength, the advantage of rubber tree sap lies in the fact that rubber tree sap is easily available around us. Also need to be pointed that the rubber tree sap was applied without any additional treatment other than tapped directly from the tree. On other hand, when using epoxy we must mix it with hardener. The most important point of using rubber tree sap will not damage the environment because the rubber tree sap is easily degraded.

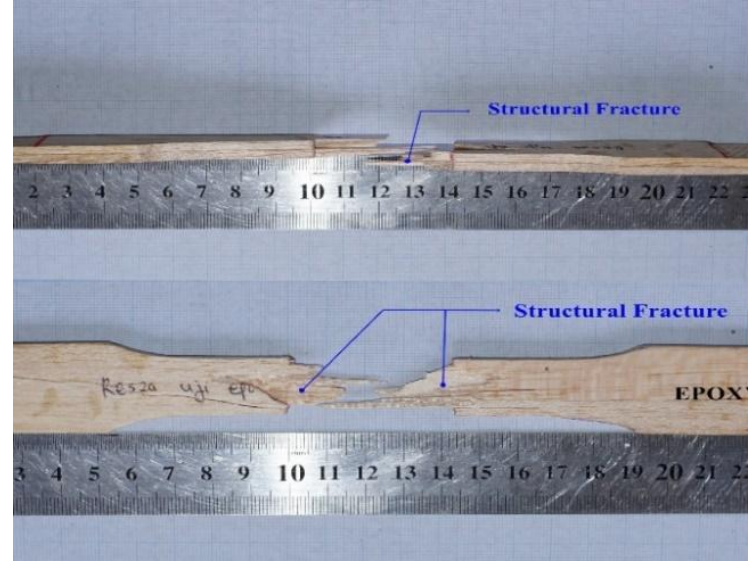

(a)

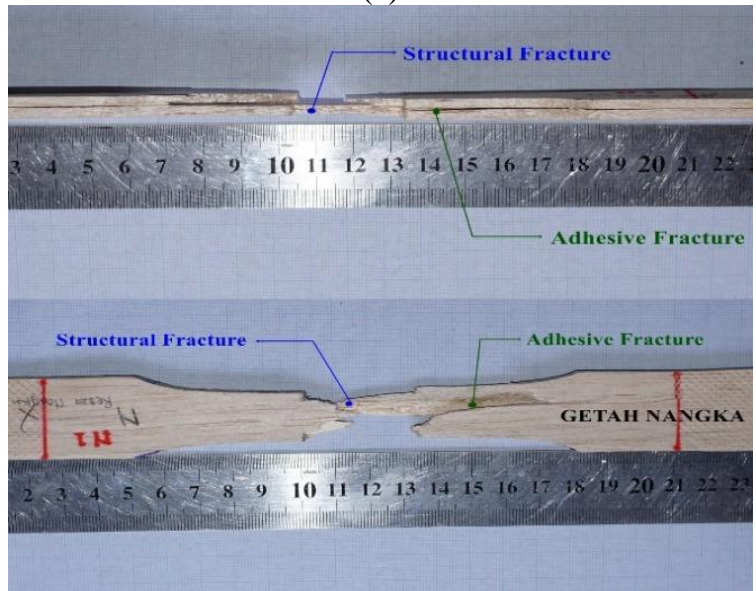

(c)
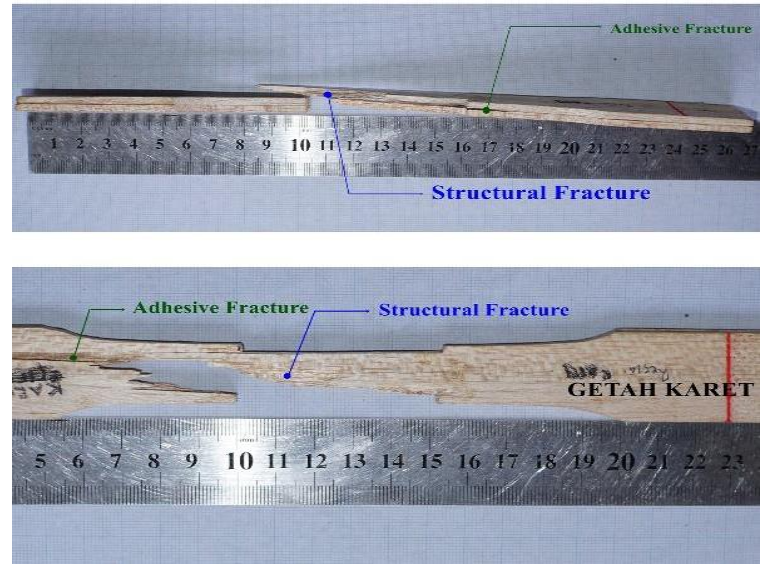

(b)

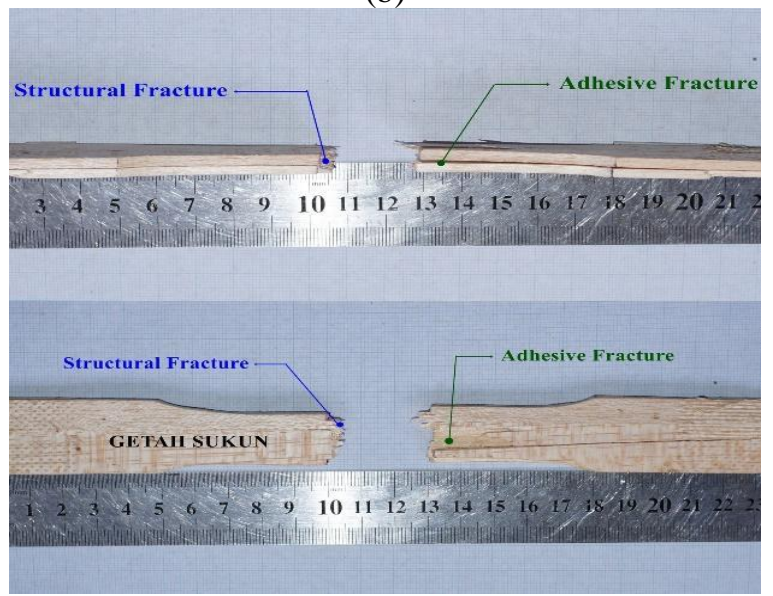

(d)

Fig. 5 - Fracture Surface of Specimen after Tensile Test.

From Figure 4 and Figure 5 (c), it can be seen that balsa wood specimens with bio-based adhesive of jackfruit tree sap show a failure in adhesive joint where the failure was a mixture failure, namely structural failure (structural fracture) and quite a lot of failure in adhesive (adhesive fracture). This is because the bonding adhesive from the sap of the jackfruit tree has not good bond strength as epoxy adhesive and bio-based rubber tree sap adhesive so that when the tensile testing was employed, it has lower tensile strength.

Also, form Figure 4 and Figure 5 (d), balsa wood specimens with bio-based adhesive of breadfruit tree sap indicated the failure of the joining adhesive of mixture failure, which were structural failure (structural fracture) and a lot of failures in adhesive (adhesive fracture). It proved that the bonding adhesive from the sap of the breadfruit tree had bonding strength not as good as the bond of the joints adhesive other so that when the tensile testing was done the value of tensile strength was the lowest. 


\subsection{Bending Strength of Balsa Wood with Variations Bio-based Adhesive}

In Figure 6 shows the comparison of bending strength of adhesive joint on balsa wood by varying bio-based adhesive. It can be seen that the order of strength of adhesive joint on balsa wood was sorted from the highest to the lowest; rubber tree sap adhesive of $23.58 \mathrm{MPa}$, jackfruit tree sap of $23.45 \mathrm{MPa}$, and the lowest was breadfruit tree sap of 19.28 MPa. This difference in strength was caused by the tree sap used in adhesive joints which balsa wood have different characteristics and sap properties.

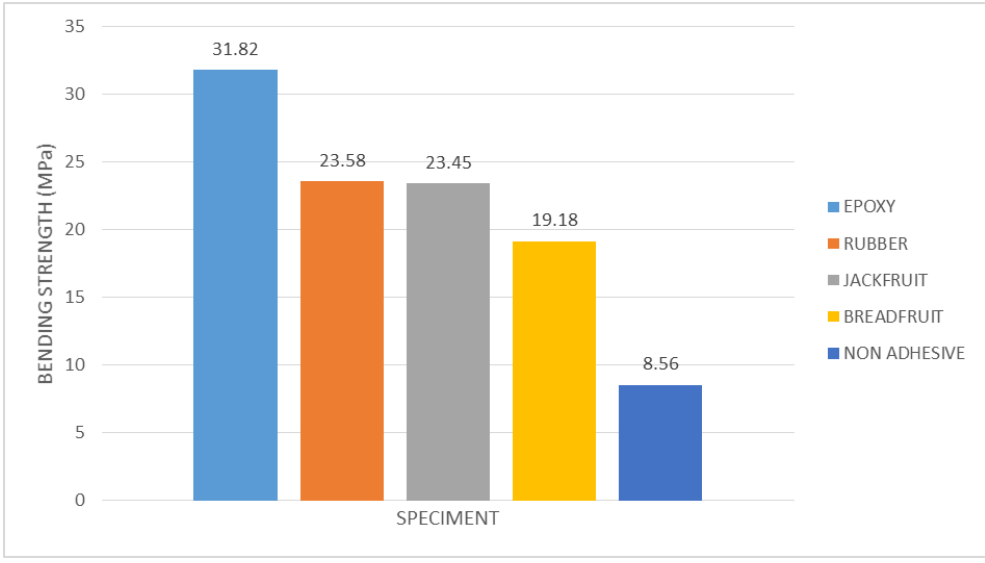

Fig. 6 - Bending strength of balsa wood sandwich with variations of adhesives

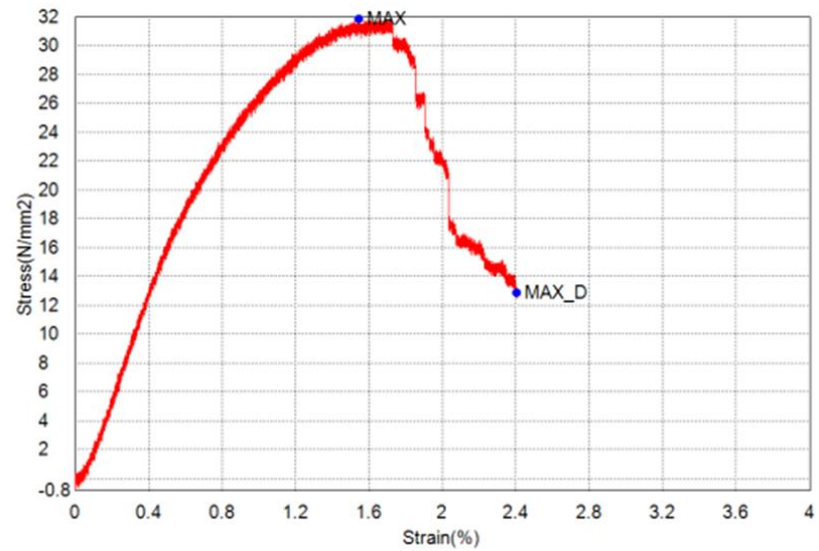

a. epoxy

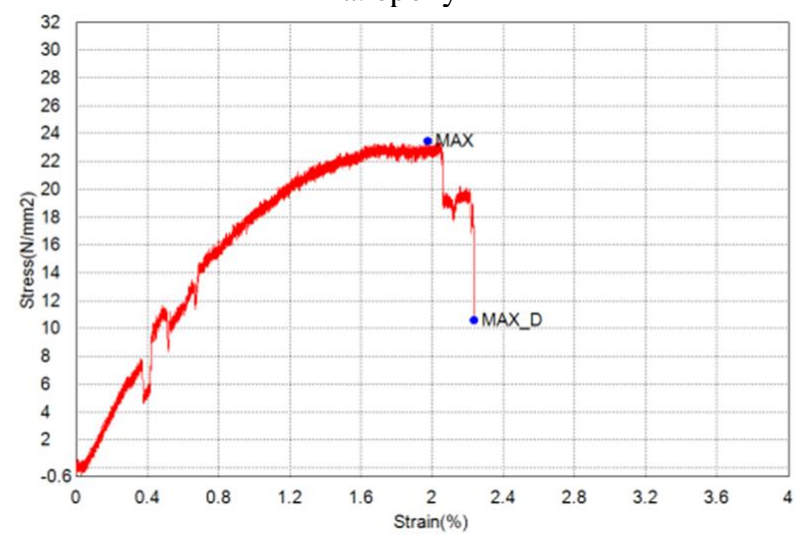

c. jackfruit sap

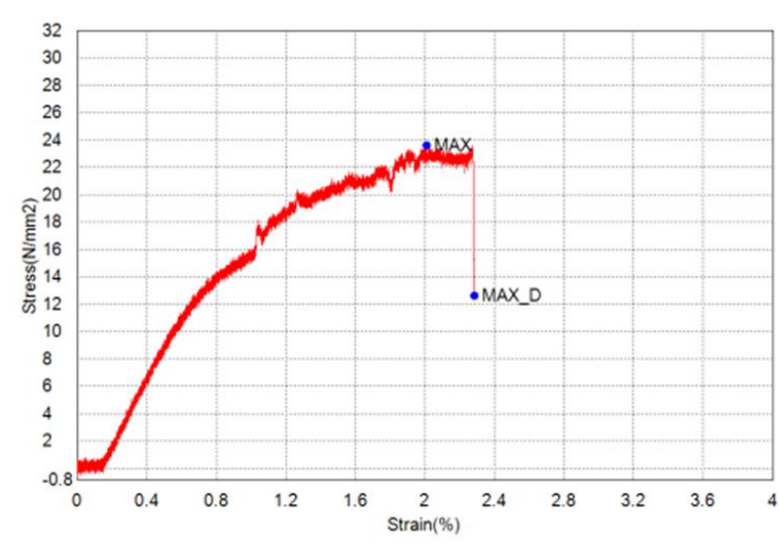

b. rubber sap

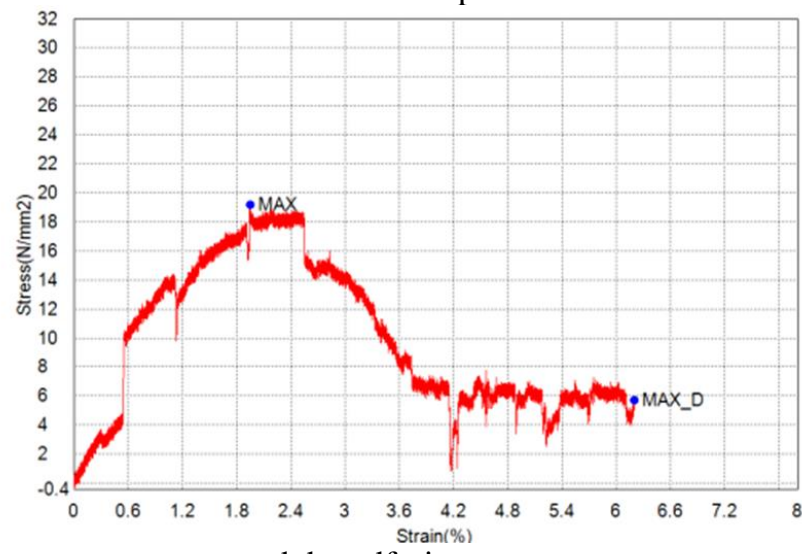

d. breadfruit sap 


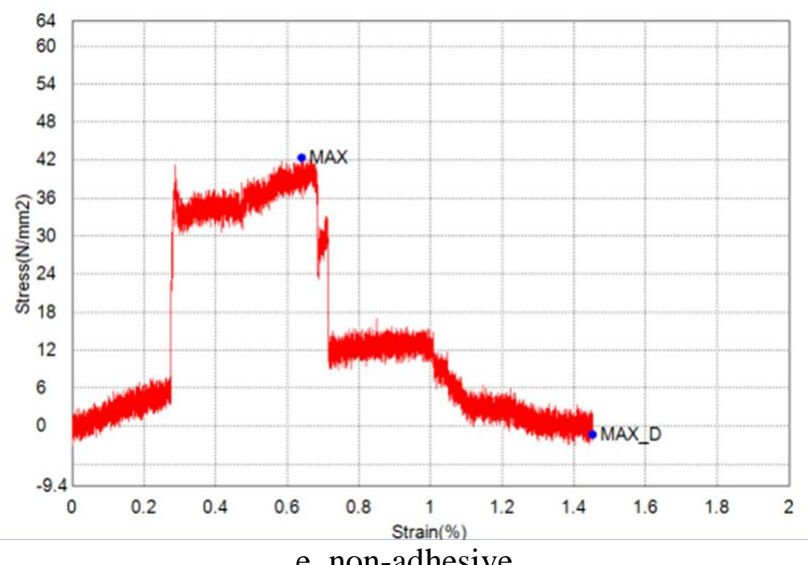

Fig. 7 - Graph of stress vs strain in bending test of adhesives joint of balsa wood.

Relationship of force-displacement on various specimens of balsa wood using adhesive joint was shown in Figure 7 of various variations of balsa wood with adhesive joints including balsa sheet, wood balsa wood with adhesive epoxy, balsa wood with bio-based adhesive rubber tree sap, balsa wood with bio-based adhesive jackfruit tree sap and balsa wood with bio-based adhesive breadfruit tree sap. From the graph, it can be seen that the $\mathrm{x}$ axis related to the displacement and the y axis related to force. In the graph, for epoxy and rubber tree sap has tendency to increase constantly to the ultimate point then experience a drops.

For jackfruit and breadfruit, it has tendency to unsmooth increase because the delamination occured faster some over $1 \mathrm{~mm}$ displacement. In the graph, there were several fluctuations in force-displacement values. The fluctuation was a representation of the occurrence of delamination on the surface adherent with adhesive. Delamination of the surface adhesive with adherent causing a decrease in the value of the strength of the bending specimen, but then rises again after adherent one is released from the others. In graphs of force-displacement on bio-based adhesive sap, breadfruit trees sap experience of fluctuations of force-displacement severely, which was caused by the adhesive is not sufficiently good to attach to the specimen surface so that there is a lot of delamination which causes a decrease in bending strength. It makes the bending strength of this one is the lowest among other specimens. Whereas on the graph of adhesive force-displacement epoxy and bio-based adhesive of rubber tree sap did not experience value fluctuations of force-displacement. It means that the 2 (two) adhesives have a better binding ability between specimen surfaces so that the strength bending is generated also higher. The other natural adhesive, i.e. sap of jackfruit trees experienced fluctuation but not as severe as breadfruit sap.

\section{Summary}

The mechanical properties of natural adhesives joint was studied by its tensile and bending strength. The potent of natural adhesive is for low loading application. The best natural adhesive, i.e. rubber tree sap, was able to compete to epoxy adhesive under 7\% strain in tensile test. The rubber tree sap cannot compete with epoxy in bending test almost in half in value but show good stability. Comparing to commercial adhesive, i.e. epoxy, the economical value of natural adhesive, especially rubber tree sap, lies on the fact that eventough it was not prepared, meaning applied directly from the tree, it still has value of $70 \%$ of epoxy adhesive tensile strength. When it coupled with degradability and non toxic feature of bio-based adhesive, then it become economically viable as alternative adhesive of epoxy for low loading application. Therefore, when special treatment to the rubber tree sap is available in improving performance of the biobased adhesive then it may compete to epoxy adhesive in higher loading application, especialy to improve the chain 4 and 5 by using additive to make adhesive-adherent able to form chemical reaction to improve bonding.

\section{References}

[1] ASTM D907-15, Standard Terminology of Adhesive, ASTM International, West Conshohocken, PA, 2015, Www.astm.org

[2] Santoso, A., 2003. Synthesis and Characterization of Lignin Resorcinol Formaldehyde Resin for Lamina Wood Adhesives. Postgraduate dissertation, Post Graduate Program, Bogor Agricultural Institute. Bogor.

[3] Sucipto, T., 2009. Wood Quantification Method, Scientific Writing Department of the Forestry Faculty of Agriculture, University of North Sumatra 
[4] International Year of Natural Fiber. 2009. Retrieved 1 August 2018, from www.fao.org/natural-fibres2009/home/en

[5] Purwanta, Jamhari Hadi et.al., 2008. Teknologi Budidaya Karet. Jakarta : Badan Penelitian dan Pengembangan Pertanian

[6] Trinihidayati. 2009. Study of latex polymers in jackfruit (Artocarpus heterophyllus Lamk), Yogyakarta: S2 Chemistry UGM

[7] Amilia, L., Muhdarina, Erman, Azman, Midiarty., 2002, Wood Waste Utilization for modification Tanin Phenol Formaldehyde Resin, Journal Natur Indonesia, 5 (1), 84 - 94

[8] Seller, T, Jr. and George, DM, Jr., 2004, Laboratory Manufacture of High Moisture Southtern Pine Stranded Bonded with Three Tannin Adhesive Type, Forest Product Journal, Vol. 54, No. 12, 296 - 301

[9] Li, J. and Maplesden, F., 1998, Commercial Production of Tannins from Radiata Pine Bark for Wood Adhesives, IPENZ Transactions, Vol. 25, No. 1, $46-52$

[10] Johar, M., Jye, W.K., and Tamin, M.N., 2018, Non-Fickian Absorption Characteristics of Adhesive Joints: Capillary Effects and Residual Properties, International Journal of Integrated Engineering: Special issue 2018, Vol. 10, No.5, 32-37.

[11] Viet, C.X., Ismail, H., Rashid, A.A., and Takeicihi, T., 2012, Kenaf Powder Filled Recycled High-Density Polyethylene/Natural Rubber Biocomposites: The Effect of Filler Content, International Journal of Integrated Engineering, Vol. 4, No. 1, 22-25

[12] Mohammad, N.A., Ahmad, S.H., Mohammad, N.E.N.A., and Hassan, N.H.M., 2018, Mechanical Properties of Epoxy Matrix Composites Toughened by Liquid Epoxidized Natural Rubber (LENR), International Journal of Integrated Engineering, Vol. 10, No. 8, 160-163.

[13] Hariyanto, A., 2006. Alkali Treatment Study and Core Thickness of the Composite and Compound Properties of Composite of Serat Kenaf Hybrid Sandwich and Polyester Polished Glass with Sea Sengon Wood Core, Thesis. Yogyakarta: Gajah Mada University.

[14] Lempang, Mody., 2016. Pemanfaatan Lignin Sebagai Bahan Perekat Kayu. Jurnal Penelitian Hasil Hutan. Balai Litbang Lingkungan Hidup dan Kehutanan, Makassar.

[15] Fadlurahman, M., Anam, K., and Ma'arif, M.S.. 2018. Pengaruh Variasi Bio Based Adhesive terhadap Kekuatan Peeling dan Shearing Kayu Pinus pada Adhesive Joint. Undergraduate Final Project, Undergraduate Program, Mechanical Engineering Department, Universitas Brawijaya. Malang.

[16] Sucipto, Tito. 2009. Analogi Ikatan Perekat Dengan Sirekat, Department of Foresty, Faculty of Agriculture, North Sumatra University.

[17] Blomquist, R.F. 1983. Fundamentals of Adhesion. In: Blomquist, R.F., Christiansen, A.W., Gillespie, R.H. and Myers, G.E. (Eds); Adhesive Bonding of Wood and Other Structural Materials. Forest Product Technology USDA Forest Service and The University of Wisconsin. Chap. 1. 